\title{
Rosuvastatin, a new HMG-CoA reductase inhibitor, reduces the colonic inflammatory response in dextran sulfate sodium-induced colitis in mice
}

\author{
YUJI NAITO $^{1}$, KAZUHIRO KATADA ${ }^{2}$, TOMOHISA TAKAGI ${ }^{3}$, HISATO TSUBOI $^{2}$, \\ YUTAKA ISOZAKI ${ }^{2}$, OSAMU HANDA ${ }^{3}$, SATOSHI KOKURA ${ }^{3}$, \\ NORIMASA YOSHIDA ${ }^{4}$, HIROSHI ICHIKAWA ${ }^{5}$ and TOSHIKAZU YOSHIKAWA ${ }^{1,2,3}$ \\ ${ }^{1}$ Department of Medical Proteomics, ${ }^{2}$ Inflammation and Immunology, ${ }^{3}$ Department of Biomedical Safety Science, \\ and ${ }^{4}$ Molecular Gastroenterology and Hepatology, Graduate School of Medical Science, Kyoto Prefectural \\ University of Medicine, Kyoto 602-8566; ${ }^{5}$ Department of Food Sciences and Nutritional Health, \\ The Faculty of Human Environment, Kyoto Prefectural University, Kyoto 606-8522, Japan
}

Received November 24, 2005; Accepted January 9, 2006

\begin{abstract}
The aim of the present study was to elucidate the beneficial effects of rosuvastatin, a new HMG-CoA reductase inhibitor, on colonic mucosal damage and on the inflammatory response in a dextran sulfate sodium (DSS) colitis model. Acute colitis was induced using $8 \%$ DSS in female BALB/c mice. Colonic mucosal inflammation was evaluated clinically, biochemically, and histologically. Mucosal protein contents and mRNA levels of tumor necrosis factor (TNF)- $\alpha$ were determined by immunoassay and real time-PCR. The mRNA levels of endothelial nitric oxide synthase (eNOS) were determined by real-time PCR. Disease activity scores in DSSinduced colitis model mice, as determined by weight loss, stool consistency, and blood in stool, were significantly lower in the rosuvastatin-treated mice than in control mice. Shortening of the colon was significantly reversed by rosuvastatin. Increases in tissue-associated myeloperoxidase activity and thiobarbituric acid-reactive substances after DSS administration were both significantly inhibited by treatment with rosuvastatin. Rosuvastatin also inhibited increases in intestinal TNF- $\alpha$ protein and mRNA expression after DSS administration, respectively. The mucosal mRNA levels of eNOS were decreased after DSS administration, but preserved in mice treated with rosuvastatin. These results suggest that rosuvastatin prevents the development of DSS-induced colitis in mice via the inhibition of mucosal inflammatory responses associated with the preservation of eNOS transcription.
\end{abstract}

Correspondence to: Dr Yuji Naito, Department of Medical Proteomics, Kyoto Prefectural University of Medicine, Kyoto 602-8566, Japan

E-mail: ynaito@koto.kpu-m.ac.jp

Key words: dextran sulfate sodium, eNOS, inflammation, neutrophil activation, rosuvastatin, tumor necrosis factor- $\alpha$

\section{Introduction}

Inflammatory bowel disease is characterized by chronic intestinal inflammation, which has two principal forms: ulcerative colitis and Crohn's disease. Recent reports have demonstrated that neutrophil infiltration in the intestinal mucosa via neutrophil-endothelial cell interactions plays a significant role in the pathogenesis of inflammatory bowel disease because activated neutrophils generate tissuedamaging products, such as reactive oxygen species, protease, collagenase, and ferrous iron complex. Leukocyte accumulation is a complex phenomenon that also involves endotheliumbased adhesion molecules as well as leukocyte-chemotaxis factors, such as interleukin-8 (IL-8). Intercellular adhesion molecules (ICAMs) are usually expressed at a low basal level but their expression can be enhanced by various inflammatory cytokines, such as IL-1 and tumor necrosis factor- $\alpha$ (TNF- $\alpha$ ) (1). A variety of cytokines, including TNF- $\alpha$, interferon- $\gamma$, and IL-1ß, are released from intestinal inflammatory mucosa. These data suggest that anti-inflammatory agents may represent a valuable therapeutic strategy for human inflammatory bowel disease (2).

3-Hydroxy-3-methylglutaryl coenzyme A (HMG-CoA) reductase inhibitors, or statins, are widely used in the treatment of hyperlipidemia and coronary artery disease (3). Accumulating evidence has suggested that statins have antiinflammatory and endothelial cell protective actions that are independent of their cholesterol-lowering effects (4). Statins can increase the expression of endothelial nitric oxide synthase (eNOS) by blocking Rho geranylgeranylation (5). Statins can block the lymphocyte function-associated antigen-1 (LFA-1)intercellular adhesion molecule-1 (ICAM-1) interaction by binding to the L-site (6). Rosuvastatin, a new HMG-CoA reductase inhibitor, has exhibited more potent affinity for the active sites of HMG-CoA reductase than other statins. In addition, the cytoprotective action of rosuvastatin against ischemic injury has been clearly documented (7-12). For example, Ikeda et al (7) demonstrated that rosuvastatin 
reduced neutrophil-induced cardiac contractile dysfunction in the isolated ischemic reperfused rat heart. However, to date, the effects of rosuvastatin on intestinal inflammation have not been investigated. The aim of the present study was to elucidate the effects of rosuvastatin on colonic mucosal damage and on the inflammatory response in a dextran sulfate sodium (DSS) colitis model. Although the pathogenesis of DSSinduced colitis is unclear, its induction may result from the toxic effects of DSS on colonic epithelial cells, alterations of luminal bacterial flora (13), or increases in oxidative and nitrosative stress (14). In addition, the cytokine expression and histological findings in acute DSS-induced colitis are very similar to those observed in human inflammatory bowel disease $(13,15)$. In the present study, special attention was paid to the effect of rosuvastatin on DSS-induced intestinal inflammatory response, including neutrophil accumulation and TNF- $\alpha$, and the effect of this agent on intestinal eNOS mRNA expression.

\section{Materials and methods}

Chemicals. All chemicals were prepared immediately before use. Rosuvastatin was donated from AstraZeneca UK, Ltd. (London, UK). Thiobarbituric acid (TBA) and 3,3',5,5'-tetramethylbenzidine were obtained from Wako Pure Chemical (Osaka, Japan). 1,1,3,3-Tetramethoxy propane was obtained from Tokyo Kasei (Tokyo, Japan). An enzyme-linked immunosorbent assay kit for mouse TNF- $\alpha$ was obtained from BioSource International (Camarillo, CA). All other chemicals were of reagent grade.

Experimental procedures. Nine-week-old female BALB/c mice weighing 18-20 g were purchased from Shimizu Experimental Animals (Osaka, Japan). The mice were caged individually in a room kept at $18-24^{\circ} \mathrm{C}$ and $40-70 \%$ relative humidity, with a 12-h light/dark cycle. They were allowed free access to their food and drinking water. The mice were fed rodent diet CE-2 (Nihon Clea, Tokyo, Japan) during their 1-week acclimatization. Then, acute colitis was induced by administering $8.0 \%$ (w/v) DSS (mol. wt 8,000; Lot No. DS-605, Seikagaku Co., Tokyo, Japan) orally in drinking water ad libitum for 7 days according to the method of previous studies $(14,16)$. Rosuvastatin was dissolved in physiologic saline. The mice were randomized into groups receiving different concentrations of rosuvastatin $(0.03,0.3$, and $3 \mathrm{mg} / \mathrm{kg} / \mathrm{day}$, or physiologic saline only, by intraperitoneal injection on each of the 7 days). The mice were sacrificed on day 7 , and their colons were removed for macroscopic and histological examination. Colonic specimens were also taken for biochemical assay and RNA isolation. The maintenance of the animals and the experimental procedures performed on them were carried out in accordance with National Institutes of Health (NIH) guidelines for the use of experimental animals. All procedures were approved by the Animal Care Committee of Kyoto Prefectural University of Medicine (Kyoto, Japan).

Evaluation of colitis severity. The parameters recorded in the experiments included the disease activity index (DAI), colon length, and histology. The DAI was determined by scoring changes in weight, occult blood positivity, gross bleeding, and
Table I. Scoring system of disease activity index (DAI).

\begin{tabular}{lccc}
\hline Score & $\begin{array}{c}\text { Weight loss } \\
(\%)\end{array}$ & $\begin{array}{c}\text { Stool } \\
\text { consistency }\end{array}$ & $\begin{array}{c}\text { Occult/gross } \\
\text { bleeding }\end{array}$ \\
\hline 0 & None & Normal & Normal \\
1 & $1-5$ & & \\
2 & $6-10$ & Loose stools & Positive occult blood test \\
3 & $11-20$ & & \\
4 & $>20$ & Diarrhea & Gross bleeding \\
\hline
\end{tabular}

The DAI is a mean of individual scores of weight loss, stool consistency, and bleeding (17-19). Normal stools, formed pellets; loose stools, pasty and semiformed stools that do not stick to the anus; diarrhea, liquid stools that stick to the anus.

stool consistency, as described previously (Table I) (17-19). Occult bleeding was tested using a commercial kit based on the detection of the peroxidase activity of heme in the stool (Occult Blood Slide 5 Shionogi; Shionogi \& Co., Osaka, Japan). The DAI score has been shown to correlate well with histological measures of inflammatory and crypt damage. We used five grades of weight loss ( 0 , no loss or weight gain; 1 , $1-5 \%$ loss; 2, 5-10\% loss; 3, 10-20\% loss; 4, >20\% loss), three grades of stool consistency ( 0 , normal; 2 , loose; and 4 , diarrhea), and three grades of occult blood ( 0 , normal; 2 , occult blood-positive; and 4, gross bleeding), and the combined scores were then divided by 3 to obtain the final DAI. After determining the DAI, the mice were sacrificed by cervical dislocation on day 7 , and the colon was resected between the ileocecal junction and the proximal rectum, close to its passage under the pelvisternum. The colon was placed on a nonabsorbent surface and measured with a ruler. The entire colon was divided into three segments (proximal, middle, and distal), and a part of each segment was fixed in $10 \%$ neutral buffered formalin. After fixation, the specimens were embedded in paraffin, divided into $7-\mu \mathrm{m}$ sections, and stained with hematoxylin and eosin.

Measurement of MPO activity and TBA-reactive substances. Tissue-associated myeloperoxidase (MPO) activity was determined by a modification of the method of Grisham et al (20) as an index of neutrophil accumulation. Two milliliters of mucosal homogenates were centrifuged at 20,000 x g for $15 \mathrm{~min}$ at $4^{\circ} \mathrm{C}$ to pellet the insoluble cellular debris. The pellet was then rehomogenized in an equivalent volume of 0.05 mol potassium phosphate buffer ( $\mathrm{pH}$ 5.4) containing $0.5 \%$ hexadecyltrimethylammonium bromide. The samples were centrifuged at $20,000 \mathrm{x}$ g for $15 \mathrm{~min}$ at $4^{\circ} \mathrm{C}$, and the supernatants were saved. MPO activity was assessed by measuring the $\mathrm{H}_{2} \mathrm{O}_{2}$-dependent oxidation of 3,3',5,5'-tetramethylbenzidine. One unit of enzyme activity was defined as the amount of MPO that caused a change in absorbance of $1.0 / \mathrm{min}$ at $655 \mathrm{~nm}$ and $25^{\circ} \mathrm{C}$.

The concentration of TBA-reactive substances was measured in the colon mucosa using the method of Ohkawa et al (21) as an index of lipid peroxidation. After the experiments, the colon mucosa was scraped off using two glass 
slides and then homogenized with $1.5 \mathrm{ml}$ of $10 \mathrm{mmol} / \mathrm{l}$ potassium phosphate buffer ( $\mathrm{pH} 7.8$ ) containing $30 \mathrm{mmol} / \mathrm{l}$ $\mathrm{KCl}$ in a Teflon Potter-Elvehjem homogenizer. The level of TBA-reactive substances in the mucosal homogenates was expressed as nanomoles of malondialdehyde per mg of protein using 1,1,3,3-tetramethoxypropane as the standard. Total protein in the tissue homogenates was measured by the method of Lowry (22).

Determination of the intestinal content of TNF- $\alpha$. We determined the concentration of TNF- $\alpha$ in the supernatant of mucosal homogenates using an enzyme-linked immunosorbent assay kit specific for mouse TNF- $\alpha$ with a sandwich method. The assay was performed according to the manufacturer's instructions. After color development, optimal densities were measured at $450 \mathrm{~nm}$ with a microplate reader (MPR A4i, Tosoh, Tokyo, Japan). The minimum detection level of TNF- $\alpha$ was $4 \mathrm{pg} / \mathrm{ml}$, and the assay has no cross-reactivity with other cytokines. The concentration of TNF- $\alpha$ was expressed as nanograms per mg of protein.

Real-time PCR for TNF- $\alpha$ and eNOS. RNA was isolated by the acid guanidinium phenol chloroform method using an Isogen kit (Nippon Gene, Tokyo, Japan). The concentration of RNA was determined by absorbance at $260 \mathrm{~nm}$ in relation to absorbance at $280 \mathrm{~nm}$. RNA was stored at $-70^{\circ} \mathrm{C}$ until reverse transcription was performed. An aliquot $(1 \mu \mathrm{g})$ of extract RNA was reverse-transcribed into first-strand complementary DNA (cDNA) at $42^{\circ} \mathrm{C}$ for $40 \mathrm{~min}$, using $100 \mathrm{U} / \mathrm{ml}$ reverse-transcriptase (Takara Biochemicals, Shiga, Japan) and $0.1 \mu \mathrm{M}$ of oligo (dT)-adapter primer (Takara) in a $50 \mu 1$ reaction mixture. Real-time polymerase chain reaction (PCR) was carried out with a 7300 Real-Time PCR system (Applied Biosystems, Foster City, CA) using the DNAbinding dye, SYBR-Green I, for the detection of PCR products. The reaction mixture (RT-PCR kit, code RRO43A, Takara) contained 12.5 $\mu 1$ Premix Ex Taq, 2.5 $\mu 1$ SYBR-Green I, custom-synthesized primers, ROX reference dye, and cDNA (equivalent to $20 \mathrm{ng}$ total RNA) to give a final reaction volume of $25 \mu 1$. The primers were as follows: for TNF- $\alpha$, sense 5'ATCCGCGACGTGGAACTG-3' and antisense 5'-ACCGCC TGGAGTTCTGGAA-3'; for eNOS, sense 5'-TCTGCGGC GATGTCACTATG-3' and antisense 5'-CATGCCGCCCTC TGTTG-3'; and for $ß$-actin, sense 5'- TGTCCACCTTCCA GCAGATGT-3' and antisense 5'- AGCTCAGTAACAGTC CGCCTAGA-3'. The PCR settings were as follows: initial denaturation of $10 \mathrm{sec}$ at $95^{\circ} \mathrm{C}$ was followed by 40 cycles of amplification for $5 \mathrm{sec}$ at $95^{\circ} \mathrm{C}$ and $31 \mathrm{sec}$ at $60^{\circ} \mathrm{C}$. The PCR products were quantified using standard DNA for each, purified by PCR products of reverse-transcribed RNA. The relative expression was then calculated as the density of the product of the respective target gene divided by that for $\beta$-actin from the same cDNA.

Superoxide and hydroxyl radical-scavenging activity. Superoxide and hydroxyl radical-scavenging activity were also measured by an ESR assay using DMPO as a spin trap. Superoxide-scavenging activity was measured by following the ESR spin-trapping method previously reported (23). Briefly, the superoxide radicals generated by the hypoxanthine-

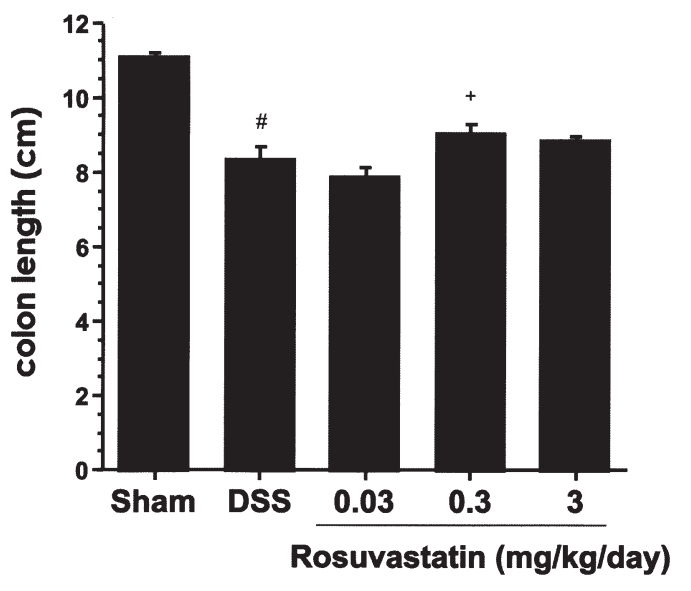

Figure 1. Effect of rosuvastatin on the total colon length after dextran sulfate sodium (DSS) administration in mice; dose-response study. Each value indicates the mean $\pm \mathrm{SE}$ for 4 mice. ${ }^{\#} \mathrm{p}<0.01$ when compared to mice receiving vehicle solution, and ${ }^{+} \mathrm{p}<0.05$ when compared to control mice receiving $8.0 \%$ DSS solution.

xanthine oxidase system were trapped by DMPO. For the actual measurements, $400 \mu \mathrm{M}$ hypoxanthine, $0.1 \mathrm{mM}$ DETAPAC, $100 \mathrm{mM}$ DMPO, the test sample, and PBS containing $1 \%$ DMF were combined, xanthine oxidase $(20 \mathrm{mU} /$ $\mathrm{ml}$ ) was added, and the signal intensity was measured $1 \mathrm{~min}$ later. For detection of hydroxyl radical-scavenging activity, we also employed the ESR spin-trapping method previously reported (24). The hydroxyl radical produced by the Fenton reaction was trapped by DMPO, and the resulting DMPO-OH signal intensity was measured. For the actual measurements, the tested sample was added to double-distilled water containing $50 \mu \mathrm{M}$ ferrous sulfate, $0.1 \mathrm{mM}$ DETAPAC, $10 \mathrm{mM}$ DMPO, and $0.4 \%$ DMF. Then, hydrogen peroxide was added at a final concentration of $1 \mathrm{mM}$, and the signal intensity was measured 1 min later. The condition of the spectrometer was the same as that used in DPPH scavenging action.

Statistics. The results are presented as the mean \pm SEM. The data were compared by two-way analysis of variance (ANOVA), and differences were considered significant if p-value based on Scheffe's multiple comparison test was 0.05. All analyses were performed using the StatView 5.0-J program (Abacus Concepts Inc. Berkeley, CA) on a Macintosh computer. Results were considered significant at a p-value of $<0.05$.

\section{Results}

Effects of rosuvastatin on DAI scores, colon length, and histology. The intake of DSS solution was monitored throughout the experiments and was found to be unchanged among the experimental groups (data not shown). Mice exposed to $8 \%$ DSS developed symptoms of acute colitis, with diarrhea followed by rectal bleeding and severe weight loss. To determine a relevant dose for the study with rosuvastatin, we first performed a dose-response study. The colon length was significantly decreased 7 days after DSS administration. In contrast, the decrease in colon length after DSS administration was significantly reversed by rosuvastatin at a dose of $0.3 \mathrm{mg} /$ 
$\mathrm{kg} /$ day (Fig. 1). Because the dose of $0.3 \mathrm{mg} / \mathrm{kg} /$ day most effectively reversed the decrease in colon length among the doses tested, we used rosuvastatin at a dose of $0.3 \mathrm{mg} / \mathrm{kg} /$ day and examined its pharmacological action in the following experiments.

DAI scores in DSS-treated mice, determined by weight loss, stool consistency, and blood in stool, were lower in the rosuvastatin-treated mice than in control mice (significant from days 3, 5 and 7; Fig. 2). Treatment with rosuvastatin alone did not increase DAI scores in sham mice. As shown in Fig. 3, shortening of the colon was observed upon removal in the control mice. In contrast, the decrease in colon length after DSS administration was significantly reversed by rosuvastatin at a dose of $0.3 \mathrm{mg} / \mathrm{kg} / \mathrm{day}$. The protective effect of rosuvastatin was also confirmed by histological study. Fig. 4 shows typical histological appearances in a rosuvastatin-treated group and in control mice. Administration of $8 \%$ DSS alone for 7 days resulted in large areas of epithelial crypt loss, prominent neutrophilic infiltration throughout the mucosa, ulceration, and mucosal bleeding. In contrast, treatment with rosuvastatin resulted in smaller erosions with fewer neutrophils.

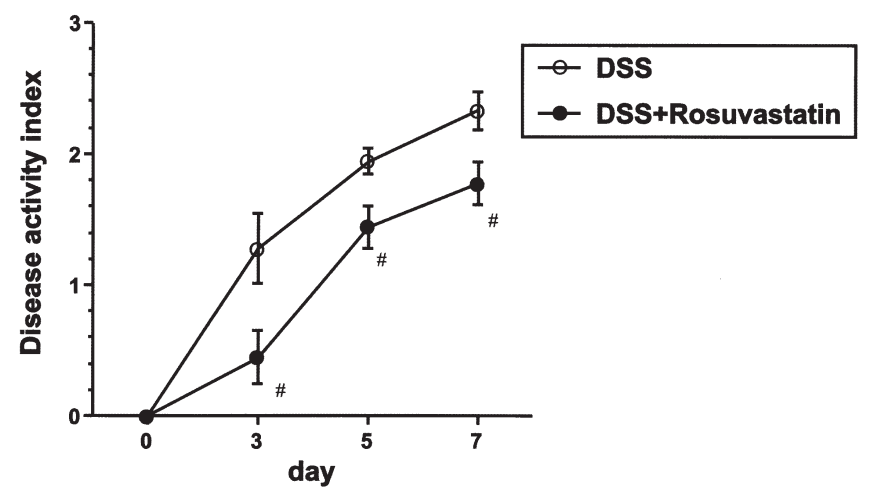

Figure 2. Effect of rosuvastatin on the disease activity index during the development of dextran sulfate sodium (DSS)-induced colitis in mice. Each value indicates the mean \pm SE for 7 mice. ${ }^{\#} \mathrm{p}<0.05$ when compared to control mice receiving $8.0 \%$ DSS solution.
Effects of rosuvastatin on MPO activity and TBA-reactive substances. Tissue-associated MPO activity in the colonic mucosa increased from $0.124 \pm 0.029 \mathrm{mU} / \mathrm{mg}$ protein, a basal concentration, to $0.564 \pm 0.141 \mathrm{mU} / \mathrm{mg}$ protein 7 days after DSS administration (Fig. 5A). The increase in MPO activity in the colonic mucosa after DSS administration was significantly inhibited by treatment with rosuvastatin. TBA-reactive substances in the colonic mucosa, an index of lipid peroxidation, increased significantly from a basal concentration of $0.54 \pm 0.05 \mathrm{nmol} / \mathrm{mg}$ protein to $1.24 \pm 0.12 \mathrm{nmol} / \mathrm{mg}$ protein 7 days after DSS administration (Fig. 5). The increase in TBAreactive substances in the colonic mucosa was significantly inhibited by rosuvastatin (Fig. 5B).
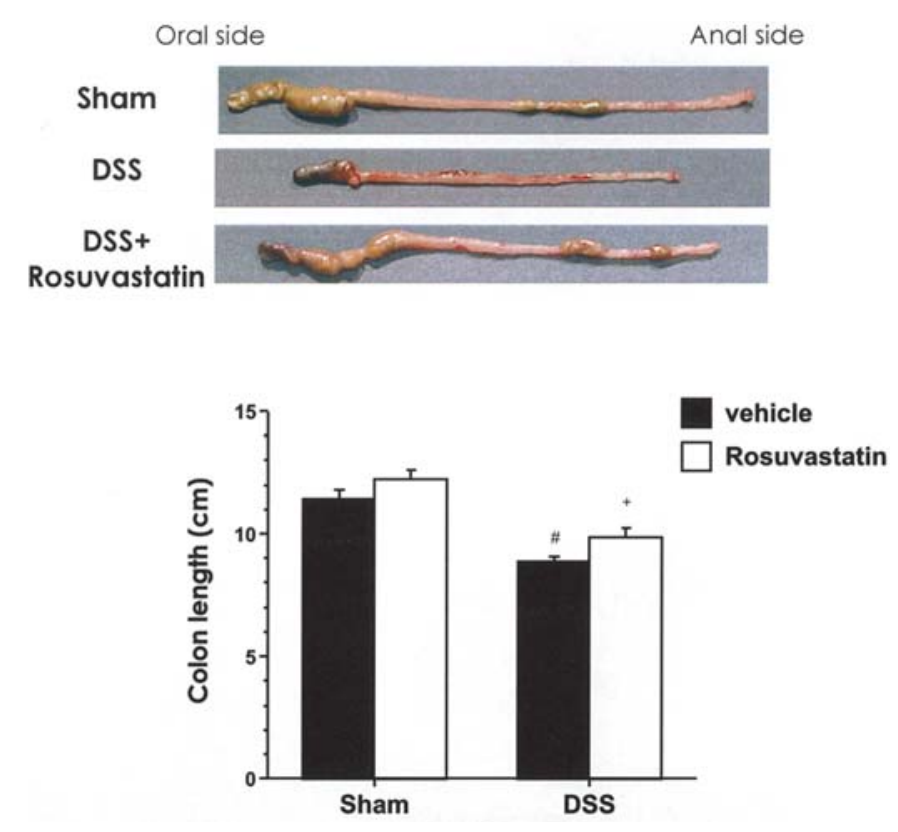

Figure 3. Effect of rosuvastatin on gross appearance (A) and length (B) of the total colon after dextran sulfate sodium (DSS) administration. Each value indicates the mean \pm SE for 7 mice. ${ }^{\#} \mathrm{p}<0.01$ when compared to the mice receiving vehicle solution, and ${ }^{+} \mathrm{p}<0.05$ when compared to control mice receiving $8.0 \%$ DSS solution.
(A)

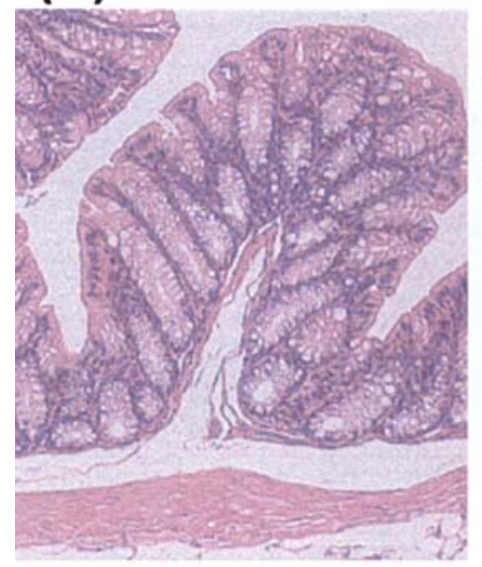

(B)

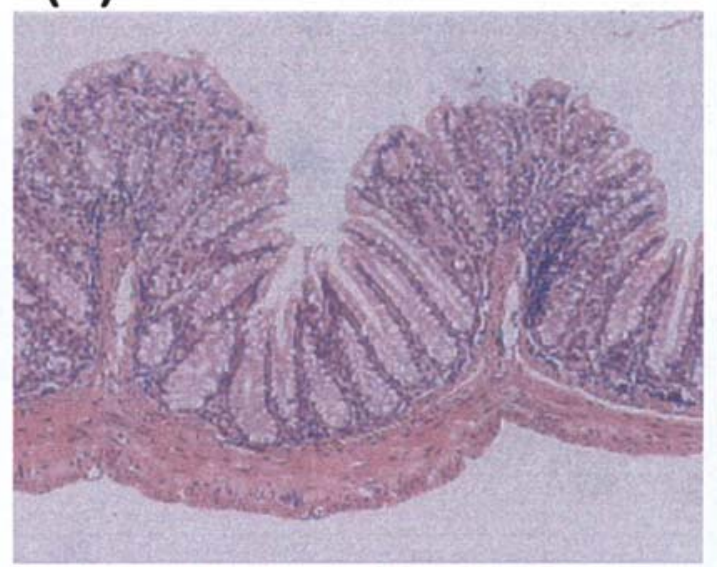

(C)

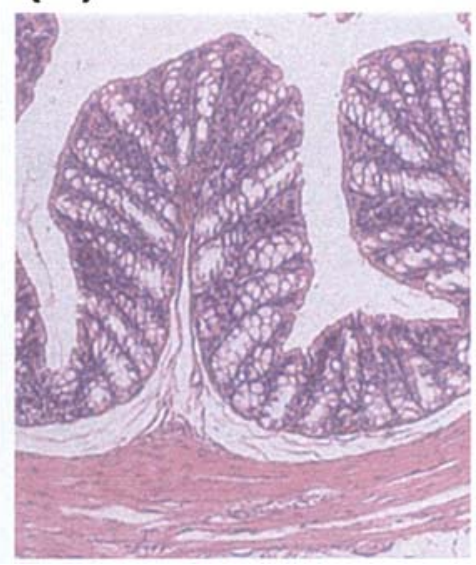

Figure 4. Appearance of the colon in a sham-treated mouse (a), a dextran sulfate sodium (DSS)-treated mouse (b), and a mouse receiving DSS plus rosuvastatin treatment (c). Loss and shortening of crypts, mucosal erosions, inflammatory cell infiltration, and goblet cell depletion are seen in (b). In (c), smaller erosions are associated with less inflammatory cell infiltration. Hematoxylin and eosin staining. Magnification, $\mathrm{x} 40$. 
(A)

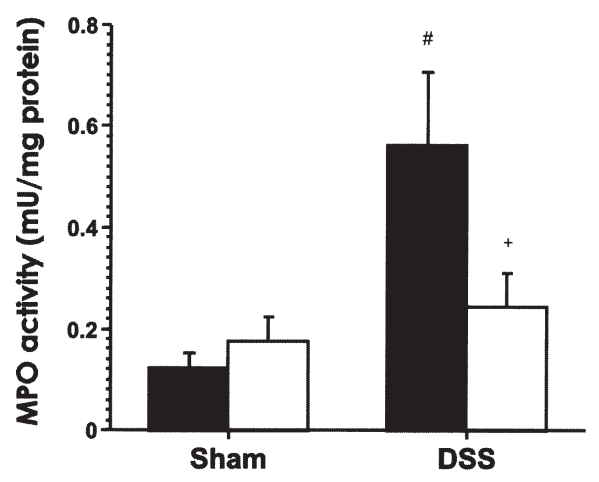

(B)

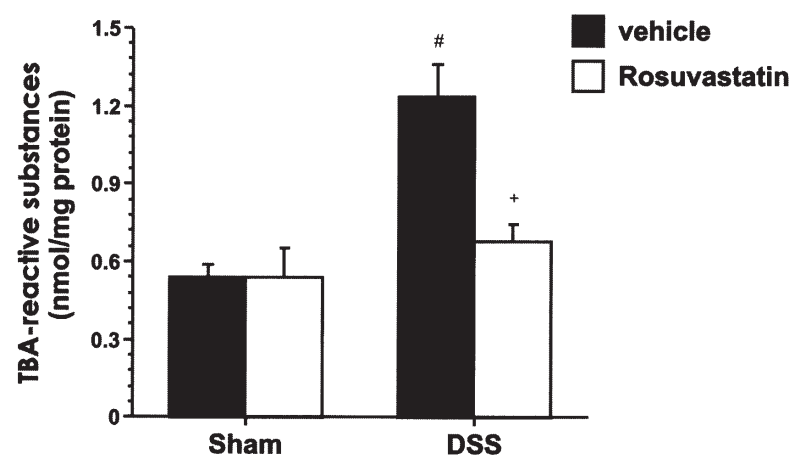

Figure 5. Effect of rosuvastatin on neutrophil accumulation expressed as myeloperoxidase (MPO) activity (A) and lipid peroxide concentration expressed as thiobarbituric acid (TBA)-reactive substances (B) in the colonic mucosa of mice administered $8 \%$ dextran sulfate sodium (DSS). Each value indicates the mean \pm SE for $6-8$ mice. ${ }^{\#} \mathrm{p}<0.01$ when compared to mice receiving vehicle solution, and ${ }^{+} \mathrm{p}<0.05$ when compared to control mice receiving $8.0 \%$ DSS solution.

(A)

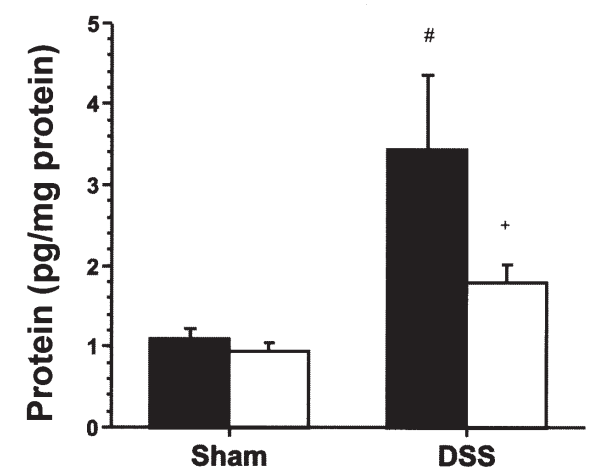

(B)

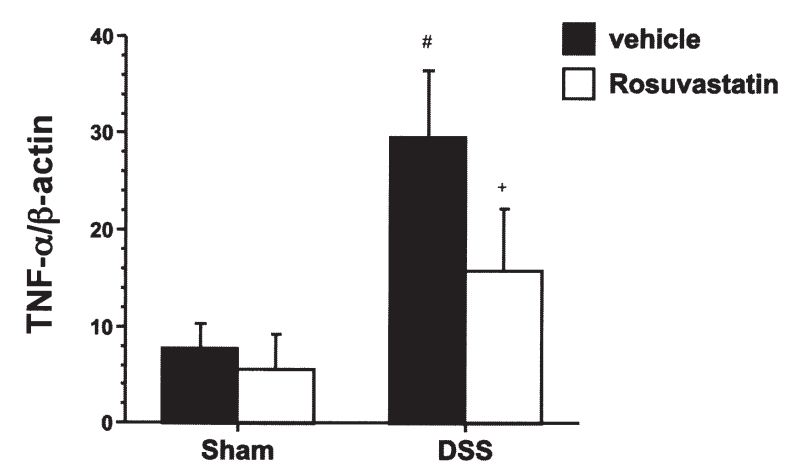

Figure 6. Effect of rosuvastatin on protein levels (A) and mRNA expression (B) of tumor necrosis factor- $\alpha$ (TNF- $\alpha$ ) in the colonic mucosa of mice administered $8 \%$ dextran sulfate sodium (DSS). Each value indicates the mean \pm SE for 6-8 mice. ${ }^{*} \mathrm{p}<0.01$ when compared to mice receiving vehicle solution, and ${ }^{+} \mathrm{p}<0.05$ when compared to control mice receiving $8.0 \%$ DSS solution.

Effect of rosuvastatin on mucosal contents and mRNA levels of $T N F-\alpha$. To test whether rosuvastatin treatment modulates the inflammatory response through regulation of cytokine production, we analyzed intestinal levels of TNF- $\alpha$. A substantial increase in mucosal TNF- $\alpha$ content was found in control mice on day 7 after DSS administration (Fig. 6B). The level of this cytokine was significantly lower in rosuvastatin-treated mice in comparison with that in control animals. To further confirm the inhibitory effect of rosuvastatin on TNF- $\alpha$ production, we analyzed the intestinal expression of TNF- $\alpha$ mRNA on day 5 after DSS administration. The expression of TNF- $\alpha$ mRNA was up-regulated in the intestine after DSS administration compared to the sham-operated group. The increased expression of TNF- $\alpha$ mRNA was significantly inhibited by rosuvastatin.

Effects of rosuvastatin on mRNA expression of eNOS. As shown in Fig. 7, the expression levels of eNOS mRNA were decreased on day 7 after DSS administration. Treatment with rosuvastatin significantly reversed the decrease in eNOS mRNA levels. Rosuvastatin alone affected the intestinal eNOS mRNA level in sham mice.
(A)

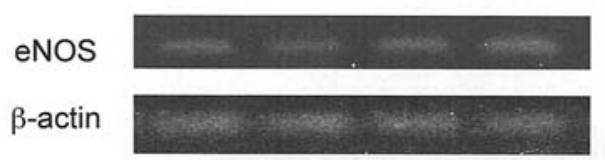

(B)

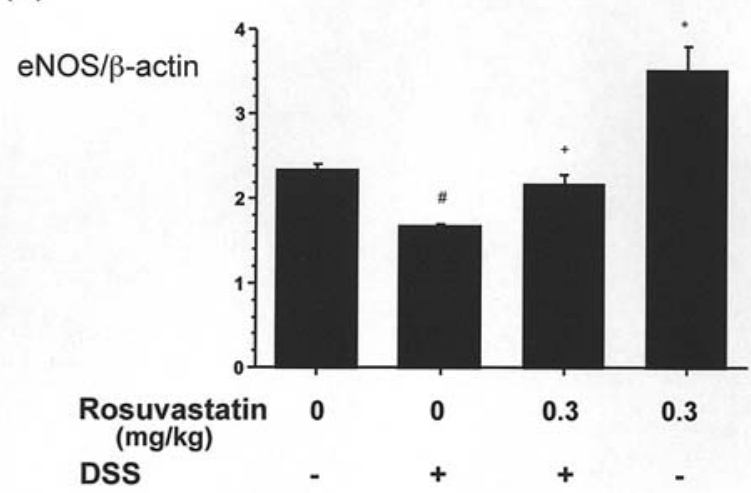

Figure 7. Effect of rosuvastatin on mRNA expression for endothelial nitric oxide synthase (eNOS) in colonic tissue from mice given $8 \%$ dextran sulfate sodium (DSS). Each value indicates the mean \pm SE for 5 mice. ${ }^{*} \mathrm{p}<0.01$ when compared to mice receiving vehicle solution, and ${ }^{+} \mathrm{p}<0.05$ when compared to control mice receiving $8.0 \%$ DSS solution. 
(A)

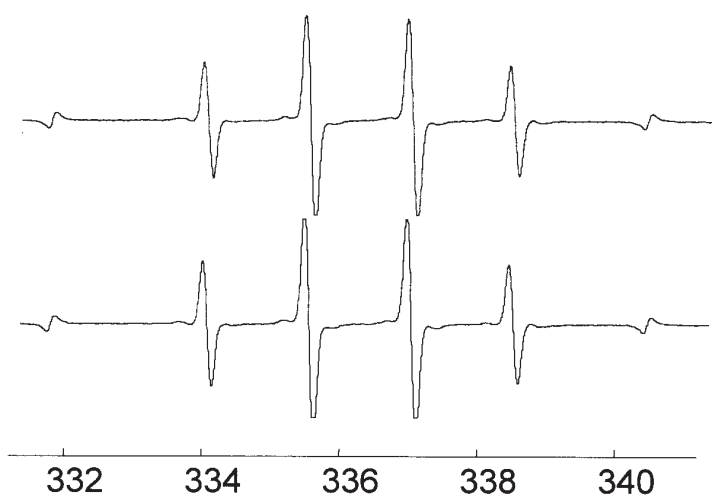

(B)
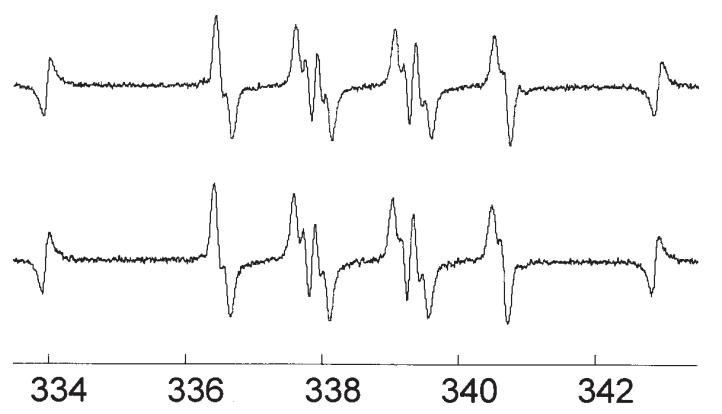

Field (mT)

Figure 8. Effects of rosuvastatin on the signal intensities of DMPO-OOH adduct (A) and DMPO-OH adduct (B) generated from the hypoxanthinexanthine oxidase system and the ferrous sulfate-hydrogen peroxide system, respectively, in the presence of DMPO. (a), vehicle; and (b), rosuvastatin (1 mM).

Effects of rosuvastatin on DMPO-OOH and DMPO-OH signals. Four characteristic signal lines of DMPO-OH, a DMPO adduct for hydroxyl radicals, were observed $1 \mathrm{~min}$ after adding hydrogen peroxide. A g-value $(2.006 \mathrm{G})$ and hyperfine coupling constant $\left(\mathrm{a}_{\mathrm{N}}=\mathrm{a}_{\mathrm{H}}=1.49 \mathrm{mT}\right)$ were assigned to the DMPO-OH spin adduct. The addition of rosuvastatin in concentrations of $1 \mathrm{mM}$ to the system did not affect the DMPO-OH signal intensity (Fig. 8A). Twelve characteristic lines of the signal of DMPO-OOH, a DMPO adduct for superoxide, were observed $1 \mathrm{~min}$ after the addition of xanthine oxidase. The g-value and hyperfine coupling constant were $\mathrm{g}=2.006 \mathrm{G}, \mathrm{a}_{\mathrm{N}}=1.41 \mathrm{mT}, \mathrm{a}_{\mathrm{H}}{ }^{\mathrm{B}}=1.13 \mathrm{mT}$, and $\mathrm{a}_{\mathrm{H}}{ }^{\gamma}=0.12 \mathrm{mT}$, which could be assigned to a DMPO-OOH adduct. The addition of rosuvastatin in concentrations of $1 \mathrm{mM}$ to the system did not affect the DMPO-OOH signal intensity (Fig. 8B).

\section{Discussion}

The present study demonstrates that chronic treatment with rosuvastatin, an HMG-CoA reductase inhibitor, attenuates DSS-induced colonic injury and inflammation in mice. In our study, intestinal injury was assessed by a variety of methods, including disease activity index, length of colon, and histology. By each assessment, rosuvastatin treatment significantly inhibited colonic injury. In addition, we showed that MPO activity, TBA-reactive substances, and the expression of the TNF- $\alpha$ gene were enhanced in DSS-induced intestinal inflammation, and that these increases were reversed by rosuvastatin treatment.

An important observation of the present study is that TBA-reactive substances, an index of lipid peroxidation, are significantly increased in the colonic mucosa after DSS administration, and that this increase is significantly inhibited by treatment with rosuvastatin. Polyunsaturated fatty acids of cell membranes are degraded by lipid peroxidation with subsequent disruption of membrane integrity, suggesting that lipid peroxidation mediated by oxygen radicals is an important cause of damage and destruction of cell membranes $(25,26)$. Our data support another recent finding in our laboratory, in which colonic TBA-reactive substances were markedly reduced by treatment with Mn-superoxide dismutase (27) and a synthetic vitamin E analogue (28) in the same DSS colitis mouse model; this suggests that induction of lipid peroxidation is an early critical event in this experimental inflammatory bowel disease model. However, the present data showed that rosuvastatin did not scavenge hydroxyl or superoxide radicals in vitro. The inhibitory effect of rosuvastatin on DSS-induced lipid peroxidation in mice colonic mucosa may result from its anti-inflammatory activity, rather than from its direct antioxidant activity.

Many investigators, including ourselves, have hypothesized that neutrophil-mediated inflammation is involved in the development of DSS-induced colonic mucosal injury. Three lines of evidence support this hypothesis: i) colonic mucosal endothelial intercellular adhesion molecule 1 (ICAM-1) expression is enhanced at an early stage in the inflammatory cascade of DSS-induced colitis (29); ii) selective depletion of neutrophils by monoclonal antibody RP-3 suppresses colitis in rats (30); and iii) immunoneutralization of ICAM-1 on endothelial cells significantly attenuates colonic mucosal injury and neutrophil accumulation in rats (31). The present study has shown that MPO activity, an index of tissueassociated neutrophil accumulation, significantly increases in the colonic mucosa after DSS administration, and that this increase is significantly inhibited by treatment with rosuvastatin. These results indicate that the inhibition of neutrophil accumulation by rosuvastatin may be one of the protective factors helping to decrease DSS-induced colonic mucosal injury. The inhibition of neutrophil-endothelial interaction by statins has also been demonstrated by previous reports. Honjo et al (32) have shown that both cerivastatin and pravastatin significantly reduced the number of rolling/ accumulated leukocytes in retinal veins after ischemiareperfusion. Naidu et al (33) have also demonstrated that pretreatment with simvastatin inhibited the increase in tissue MPO content in lungs treated with ischemia-reperfusion. However, the mechanism by which these statins may be involved in the infiltration of neutrophils remains to be established and is currently undergoing investigation.

TNF- $\alpha$ has recently attracted attention due to its key role in the pathogenesis of inflammatory bowel disease; clinical trials have reported a marked improvement in patients with Crohn's disease treated with high-affinity chimeric and humanized monoclonal antibody directed against TNF- $\alpha$ (34), corroborating the concept of interference with the 
function of TNF- $\alpha$ in inflammatory bowel disease. Previous reports of DSS colitis in mice have emphasized the involvement of T-helper 1 responses in the production of $\mathrm{TNF}-\alpha$ in this model of colitis; treatment with anti-TNF- $\alpha$ antibody markedly decreased the severity (35). We also previously reported that the inhibition of TNF- $\alpha$ expression by pioglitazone, a peroxisome proliferator-activated receptor- $\gamma$ ligand, was accompanied by significant suppression of intestinal inflammation in the same model (36). Therefore, we tested the effects of rosuvastatin on inflammatory responses after the induction of colitis. In the present study, we confirmed the anti-inflammatory properties of rosuvastatin in vivo by demonstrating the reduction of mucosal TNF- $\alpha$ protein contents as well as down-regulation of the gene expression in inflamed mucosa. The inhibitory effects of rosuvastatin on TNF- $\alpha$ production were also confirmed by a previous study in which rosuvastatin specifically suppressed the expression of TNF- $\alpha$ in the vessel wall of atherosclerotic mice, independent of its cholesterol-lowering effect (37).

The beneficial effects of statins on acute inflammation were abolished when co-administered with an NOS inhibitor $(11,38)$ or when administered to eNOS knockout mice $(39,40)$. Sasaki et al (40) have reported that the protective effects of pravastatin, an HMG CoA reductase inhibitor, in DSS-induced colitis are not found in eNOS-deficient mice. These data obtained from in vivo experiments indicate that enhanced release of NO from eNOS may be involved in the action of statins. Statins are known to up-regulate eNOS expression and to activate this enzyme in the systemic vasculature by blocking Rho geranylgeranylation $(5,41)$ as well as by activating the PI-3 kinase/Akt pathway (38). As shown in the present study, the intestinal levels of eNOS mRNA decreased after DSS administration, and rosuvastatin-treated animals demonstrated preserved expression of eNOS mRNA compared to the control group; in addition, this agent enhanced the level of eNOS mRNA in sham mice. Therefore, the persistent expression of eNOS mRNA during DSS administration in rosuvastatin-treated mice probably explains the reduction in tissue injury by prevention of endothelial dysfunction and the reduction in neutrophil accumulation by inhibition of leukocyte-endothelial adhesion. In line with our observation, $\mathrm{NO}$ is reported to prevent leukocyte adhesion to the endothelium by repressing the up-regulation of cell adhesion molecules in endothelial cells $(42,43)$. Sironi et al (12) have recently reported that rosuvastatin inhibits endothelial cell surface expression of P-selectin, an adhesion molecule that plays a pivotal role in leukocyte-endothelium interactions.

Our results show that DSS-induced intestinal inflammation is characterized by neutrophil accumulation and increased expression of TNF- $\alpha$. Inhibition of TNF- $\alpha$ and up-regulation of eNOS transcription by rosuvastatin treatment was accompanied by significant suppression of intestinal inflammation in vivo. These data suggest that rosuvastatin may be an alternative therapeutic strategy for inflammatory bowel disease.

\section{Acknowledgements}

This work was supported by Grants-in-Aid for Scientific Research (14570493 YN and 15390178 TY) from the Ministry of Education, Culture, Sports, Science and Technology of
Japan, by a grant from Bio-oriented Technology Research Advancement Institution, and by a grant from the Ministry of Agriculture, Forestry and Fisheries of Japan.

\section{References}

1. Vainer B: Intercellular adhesion molecule-1 (ICAM-1) in ulcerative colitis: presence, visualization, and significance. Inflamm Res 54: 313-327, 2005.

2. Harlan JM and Winn RK: Leukocyte-endothelial interactions: clinical trials of anti-adhesion therapy. Crit Care Med 30: S214-S219, 2002.

3. Maron DJ, Fazio S and Linton MF: Current perspectives on statins. Circulation 101: 207-213, 2000.

4. Oda $\mathrm{H}$ and Keane WF: Recent advances in statins and the kidney. Kidney Int Suppl 71: S2-S5, 1999.

5. Endres $M$ and Laufs U: Effects of statins on endothelium and signaling mechanisms. Stroke 35: 2708-2711, 2004.

6. Weitz-Schmidt G, Welzenbach K, Brinkmann V, et al: Statins selectively inhibit leukocyte function antigen-1 by binding to a novel regulatory integrin site. Nat Med 7: 687-692, 2001.

7. Ikeda Y, Young LH and Lefer AM: Rosuvastatin, a new HMG-CoA reductase inhibitor, protects ischemic reperfused myocardium in normocholesterolemic rats. J Cardiovasc Pharmacol 41: 649-656, 2003.

8. Bulhak A, Sjoquist PO and Pernow J: Rosuvastatin protects the myocardium against ischaemia-reperfusion injury via inhibition of GGPP synthesis. Cardiovasc J S Afr 15: S11, 2004.

9. Bulhak AA, Gourine AV, Gonon AT, Sjoquist PO, Valen G and Pernow J: Oral pre-treatment with rosuvastatin protects porcine myocardium from ischaemia/reperfusion injury via a mechanism related to nitric oxide but not to serum cholesterol level. Acta Physiol Scand 183: 151-159, 2005.

10. Weinberg EO, Scherrer-Crosbie M, Picard MH, et al: Rosuvastatin reduces experimental left ventricular infarct size after ischemia-reperfusion injury but not total coronary occlusion. Am J Physiol Heart Circ Physiol 288: H1802-H1809, 2005.

11. Di Napoli P, Taccardi AA, Grilli A, et al: Chronic treatment with rosuvastatin modulates nitric oxide synthase expression and reduces ischemia-reperfusion injury in rat hearts. Cardiovasc Res 66: 462-471, 2005.

12. Sironi L, Gianazza E, Gelosa P, et al: Rosuvastatin, but not simvastatin, provides end-organ protection in stroke-prone rats by antiinflammatory effects. Arterioscler Thromb Vasc Biol 25: 598-603, 2005.

13. Okayasu I, Hatakeyama S, Yamada M, Ohkusa T, Inagaki Y and Nakaya R: A novel method in the induction of reliable experimental acute and chronic ulcerative colitis in mice. Gastroenterology 98: 694-702, 1990.

14. Naito Y, Takagi T, Ishikawa T, et al: The inducible nitric oxide synthase inhibitor ONO-1714 blunts dextran sulfate sodium colitis in mice. Eur J Pharmacol 412: 91-99, 2001.

15. Egger B, Bajaj-Elliott M, MacDonald TT, Inglin R, Eysselein VE and Buchler MW: Characterisation of acute murine dextran sodium sulphate colitis: cytokine profile and dose dependency. Digestion 62: 240-248, 2000.

16. Naito Y, Takagi T, Ishikawa $\mathrm{T}$, et al: alpha-Phenyl-N-tertbutylnitrone provides protection from dextran sulfate sodiuminduced colitis in mice. Antioxid Redox Signal 4: 195-206, 2002.

17. Cooper HS, Murthy SN, Shah RS and Sedergran DJ: Clinicopathologic study of dextran sulfate sodium experimental murine colitis. Lab Invest 69: 238-249, 1993.

18. Naito Y, Takagi T, Kuroda M, et al: An orally active matrix metalloproteinase inhibitor, ONO-4817, reduces dextran sulfate sodium-induced colitis in mice. Inflamm Res 53: 462-468, 2004.

19. Naito Y, Takagi T, Katada K, et al: Partially hydrolyzed guar gum down-regulates colonic inflammatory response in dextran sulfate sodium-induced colitis in mice. J Nutr Biochem (In press).

20. Grisham MB, Hernandez LA and Granger DN: Xanthine oxidase and neutrophil infiltration in intestinal ischemia. Am J Physiol 252: G567-G574, 1986.

21. Ohkawa H, Ohnishi N and Yagi K: Assay for lipid peroxides for animal tissues by thiobarbituric acid reaction. Anal Biochem 95: 351-358, 1986. 
22. Lowry OH, Rosenbrough NJ, Farr AL and Randall RJ: Protein measurement with the folin phenol reagent. J Biol Chem 193: 265-275, 1951 .

23. Miyagawa H, Yoshikawa T, Tanigawa T, Yoshida N, Sugino S and Kondo M: Measurement of serum superoxide dismutase activity by electron spin resonance. J Clin Biochem Nutr 5: 1-7, 1988.

24. Tanigawa T: Determination of hydroxyl radical scavenging activity by electron spin resonance. J Kyoto Pref Univ Med 99: 133-143, 1990.

25. Niki E and Komuro E: Inhibition of peroxidation of membranes. Basic Life Sci 49: 561-566, 1988.

26. Niki E, Noguchi N and Gotoh N: Dynamics of lipid peroxidation and its inhibition by antioxidants. Biochem Soc Trans 21: 313-317, 1993.

27. Naito Y, Takagi T, Handa O, et al: Role of superoxide and lipid peroxidation in the pathogenesis of dextran sulfate sodiumcolitis in mice. ITE Lett 2: 663-667, 2001.

28. Naito Y, Takagi T, Matsuyama K, et al: Effect of a novel watersoluble vitamin E derivative, 2-(a-D-glucopyranoyl)methyl2,5,7,8-tetramethylchroman-6-ol, on dextran sulfate sodiuminduced colitis in mice. J Clin Biochem Nutr 31: 59-67, 2002.

29. Breider MA, Eppinger M and Gough A: Intercellular adhesion molecule-1 expression in dextran sodium sulfate-induced colitis in rats. Vet Pathol 34: 598-604, 1997.

30. Natsui M, Kawasaki K, Takizawa H, et al: Selective depletion of neutrophils by a monoclonal antibody, RP-3, suppresses dextran sulphate sodium-induced colitis in rats. J Gastroenterol Hepatol 12: 801-808, 1997.

31. Taniguchi T, Tsukada H, Nakamura $\mathrm{H}$, et al: Effects of the antiICAM-1 monoclonal antibody on dextran sodium sulphateinduced colitis in rats. J Gastroenterol Hepatol 13: 945-949, 1998.

32. Honjo M, Tanihara H, Nishijima K, et al: Statin inhibits leukocyte-endothelial interaction and prevents neuronal death induced by ischemia-reperfusion injury in the rat retina. Arch Ophthalmol 120: 1707-1713, 2002.

33. Naidu BV, Woolley SM, Farivar AS, Thomas R, Fraga C and Mulligan MS: Simvastatin ameliorates injury in an experimental model of lung ischemia-reperfusion. J Thorac Cardiovasc Surg 126: 482-489, 2003.
34. Rutgeerts PJ: Review article: efficacy of infliximab in Crohn's disease - induction and maintenance of remission. Aliment Pharmacol Ther 13: 9-15; discussion 38, 1999.

35. Kojouharoff G, Hans W, Obermeier F, et al: Neutralization of tumour necrosis factor (TNF) but not of IL-1 reduces inflammation in chronic dextran sulphate sodium-induced colitis in mice. Clin Exp Immunol 107: 353-358, 1997.

36. Takagi T, Naito Y, Tomatsuri N, et al: Pioglitazone, a PPARgamma ligand, provides protection from dextran sulfate sodium-induced colitis in mice in association with inhibition of the NF-kappaB-cytokine cascade. Redox Rep 7: 283-289, 2002.

37. Kleemann R, Princen HM, Emeis JJ, et al: Rosuvastatin reduces atherosclerosis development beyond and independent of its plasma cholesterol-lowering effect in APOE*3-Leiden transgenic mice: evidence for antiinflammatory effects of rosuvastatin. Circulation 108: 1368-1374, 2003.

38. Wolfrum S, Dendorfer A, Schutt M, et al: Simvastatin acutely reduces myocardial reperfusion injury in vivo by activating the phosphatidylinositide 3-kinase/Akt pathway. J Cardiovasc Pharmacol 44: 348-355, 2004.

39. Endres M, Laufs U, Huang Z, et al: Stroke protection by 3hydroxy-3-methylglutaryl (HMG)-CoA reductase inhibitors mediated by endothelial nitric oxide synthase. Proc Natl Acad Sci USA 95: 8880-8885, 1998.

40. Sasaki M, Bharwani S, Jordan P, et al: The 3-hydroxy-3methylglutaryl-CoA reductase inhibitor pravastatin reduces disease activity and inflammation in dextran-sulfate induced colitis. J Pharmacol Exp Ther 305: 78-85, 2003.

41. Laufs U, La Fata V, Plutzky J and Liao JK: Upregulation of endothelial nitric oxide synthase by HMG CoA reductase inhibitors. Circulation 97: 1129-1135, 1998.

42. Kubes P, Suzuki M and Granger DN: Nitric oxide: an endogenous modulator of leukocyte adhesion. Proc Natl Acad Sci USA 88: 4651-4655, 1991.

43. Lefer AM: Nitric oxide: nature's naturally occurring leukocyte inhibitor. Circulation 95: 553-554, 1997. 